Tropical Journal of Pharmaceutical Research October 2013; 12 (5): 711-718

ISSN: $1596-5996$ (print); 1596-9827 (electronic)

(c) Pharmacotherapy Group, Faculty of Pharmacy, University of Benin, Benin City, 300001 Nigeria.

All rights reserved.

Available online at http://www.tjpr.org

Original Research Article

http://dx.doi.org/10.4314/tjpr.v12i5.8

\title{
Enhancing the Production of a Novel Exopolysaccharide by Bacillus mucilaginosus CGMCC5766 Using Statistical Experiment Design
}

\author{
Hui $\mathrm{Li}^{1}$, Jie $\mathrm{Li}^{1}$, Wenfang Dou ${ }^{1}$, Jinsong Shi ${ }^{1 \star}$ and Zhenghong $\mathrm{Xu}^{1}$ \\ ${ }^{1}$ Laboratory of Pharmaceutical Engineering, School of Pharmaceutical Science, Jiangnan University, ${ }^{2}$ The Key Laboratory of \\ Industrial Biotechnology, Ministry of Education, Jiangnan University, Wuxi 214122, PR China
}

*For correspondence: Email: shijs@163.com; Tel: +86-510-85328177; Fax: +86-510-85328177

Received: 18 October 2012

Revised accepted: 25 July 2013

\begin{abstract}
Purpose: To improve the production of a novel exopolysaccharide (EPS) by Bacillus mucilaginosus CGMCC5766.

Methods: The culture medium for production of EPS was optimized using statistical experiment design. Sucrose, $\mathrm{CaCO}_{3}$ and $\mathrm{K}_{2} \mathrm{HPO}_{4}$ were found to be the key factors based on the results obtained from Plackett-Burman experimental design. The optimal concentration range of the three factors was examined by the steepest ascent path, and then the optimum concentration was further investigated through response surface methodology. Validation experiments were also carried out to establish the adequacy and accuracy of the model obtained.

Results: Under optimal conditions (sucrose $61.31 \mathrm{~g} / \mathrm{l}, \mathrm{CaCO}_{3} 5.06 \mathrm{~g} / \mathrm{l}$ and $\mathrm{K}_{2} \mathrm{HPO}_{4} 0.17 \mathrm{~g} / \mathrm{ll}$ ), EPS concentration achieved $22.04 \mathrm{~g} / \mathrm{l}$, which was about 1.6-fold increase compared with that using the original medium. EPS concentration in 5-I fermenter reached $23.46 \pm 0.76 \mathrm{~g} / \mathrm{l}$.

Conclusion: The optimization medium is considered fundamental and useful for the development of $B$. mucilaginosus CGMCC5766 cultivation process for efficient production of EPS on a large scale.

Keywords: Bacillus mucilaginosus CGMCC5766, Exopolysaccharide, Medium, Optimization, Statistical experiment design

Tropical Journal of Pharmaceutical Research is indexed by Science Citation Index (SciSearch), Scopus, International Pharmaceutical Abstract, Chemical Abstracts, Embase, Index Copernicus, EBSCO, African Index Medicus, JournalSeek, Journal Citation Reports/Science Edition, Directory of Open Access Journals (DOAJ), African Journal Online, Bioline International, Open-J-Gate and Pharmacy Abstracts
\end{abstract}

\section{INTRODUCTION}

Microorganism exopolysaccharides (EPSs) are biopolymers which either attach to the cell surface or are excreted in the extracellular medium in the form of amorphous slime [1]. Many microorganisms have been shown to produce EPS e.g., Xanthomonas campestris [2], Pseudomonas aeruginosa [3], Sphingomonas paucimobilis [4], Streptococcus zooepidemicus [5], Haloferax mediterranei [6]. Due to their many interesting physical and chemical properties, microbial EPS are also widely used in several fields such as food, coating materials, medicine, concrete additives, enhanced oil recovery and wastewater treatment as a suspending, stabilizing, emulsifying, thickening agent and flocculants [1]. There has been growing interest in novel microbial polysaccharides with improved properties.

It has also been found that Bacillus mucilaginosus can secrete an EPS which may be used as a bioflocculant in wastewater treatment to remove various contaminants [7]. Although it has been several years since EPS from $B$. mucilaginosus was first discovered, the process for the production has not been thoroughly 
studied. Many researchers have focused their efforts on the characteristics and the applications of EPS from B. mucilaginosus [8, 9, 10]. However, there are very few reports concerning culture medium and process parameters optimization. Moreover, the high cost and low yields of bioflocculant are the major factors limiting the development of bioflocculants for commercial use in wastewater treatment. Thus, it is also important to reduce the costs of the medium as this may affect the overall process economics.

Statistical experiment design and data analysis have been applied successfully for optimizing the medium constituents and other critical variables responsible for the production of EPS [11-13]. Response surface methodology (RSM) is a powerful statistical tool for testing multiple process variables. This methodology could overcome the limitations of single-parameter optimization, which is both time-consuming and cannot assess the complex interactions among the various physico-chemical parameters [14]. Prior to optimization using RSM, PlackettBurman ( $\mathrm{P}-\mathrm{B})$ design has been frequently used for screening the key factors in recent years [15, 16]. It is successfully used for optimization studies in several biotechnological and industrial processes [17, 18].

In this study, a novel exopolysaccharide bioflocculant was produced by $B$. mucilaginosus CGMCC5766 which was isolated from a mountainous district of Shandong in China. Its average molecular weight was about $2.299 \times 10^{6}$ Da. The chemical components and primary structure of the obtained EPS was studied by GC, FTIR, NMR methods during our previous study [19]. The results indicated that EPS was a hetero-polysaccharide constituted by mannose, glucose and galactose at a molar ratio of 2:1.6:1. Its backbone was composed of glucose through $\beta$-glycosidic linkage while the lateral branches were composed of mannose and galactose by $\alpha$ glycosidic linkage. Up to now, a related structure has not been reported. Promising results of preliminary research showed that EPS is efficient in flocculating inorganic solid suspensions, heavy metal ions, dyes solution and other synthetic suspensions in many types of wastewaters. To improve the production of EPS, the culture medium for fermentation of EPS from $B$. mucilaginosus CGMCC5766 was studied. The optimization of the medium was carried out by means of the P-B experimental design, the path of steepest ascent and response surface methodology.

\section{EXPERIMENTAL}

\section{Bacterium}

B. mucilaginosus CGMCC5766 was isolated from a mountainous district in Shandong, China. A specimen was deposited in the China General Microbiological Culture Collection Center.

\section{Medium and cultivation conditions}

The medium for agar slant consisted of $10 \mathrm{~g} / \mathrm{l}$ sucrose, $0.1 \mathrm{~g} / \mathrm{l}\left(\mathrm{NH}_{4}\right)_{2} \mathrm{SO}_{4}, 0.2 \mathrm{~g} / \mathrm{l} \mathrm{K} \mathrm{HPO}_{4}, 0.2$ $\mathrm{g} / \mathrm{l} \mathrm{NaCl}, 0.2 \mathrm{~g} / \mathrm{MgSO}_{4}, 2 \mathrm{~g} / \mathrm{l} \mathrm{CaCO}_{3}$ and $20 \mathrm{~g} / \mathrm{l}$ agar. The seed medium contained $10 \mathrm{~g} / \mathrm{l}$ sucrose, $0.1 \mathrm{~g} / \mathrm{l}$ urea, $0.2 \mathrm{~g} / \mathrm{l} \mathrm{K}_{2} \mathrm{HPO}_{4}, 0.2 \mathrm{~g} / \mathrm{l}$ $\mathrm{NaCl}, 0.2 \mathrm{~g} / \mathrm{l} \mathrm{MgSO}_{4}$ and $5 \mathrm{~g} / \mathrm{l} \mathrm{CaCO}_{3}$. The original fermentation medium included $30 \mathrm{~g} / \mathrm{l}$ sucrose, $0.1 \mathrm{~g} / \mathrm{l}$ urea, $0.2 \mathrm{~g} / \mathrm{l} \mathrm{K}_{2} \mathrm{HPO}_{4}, 0.2 \mathrm{~g} / \mathrm{l}$ $\mathrm{NaCl}, 0.2 \mathrm{~g} / \mathrm{MgSO}_{4}$ and $5 \mathrm{~g} / \mathrm{CaCO}_{3}$. The initial $\mathrm{pH}$ was adjusted to $7.0-7.2$ by $2 \mathrm{~mol} / \mathrm{l} \mathrm{HCl}$ throughout the work.

For seed preparation, a loop of $B$. mucilaginosus CGMCC5766 cells was inoculated into $30 \mathrm{ml}$ of sterile seed medium in 250-ml Erlenmeyer flasks and incubated for $24 \mathrm{~h}$ at $30{ }^{\circ} \mathrm{C}$ with shaking at $200 \mathrm{rpm}$. Inoculum (5\%, v/v) was transferred into $500-\mathrm{ml}$ Erlenmeyer flasks containing $50 \mathrm{ml}$ of fermentation medium whose composition was varied based on the experimental designs and aerobically incubated for $66 \mathrm{~h}$ at $30{ }^{\circ} \mathrm{C}$ and 200 $\mathrm{rpm}$ in a rotatory shaker. The initial $\mathrm{pH}$ was adjusted to $7.0-7.2$ by $2 \mathrm{~mol} / \mathrm{l} \mathrm{HCl}$. All medium were autoclaved for $20 \mathrm{~min}$ at $121^{\circ} \mathrm{C}$. Each experiment was repeated thrice and the mean value was calculated.

\section{Analytical methods}

The optical density (OD) of the microbial cell was measured at $600 \mathrm{~nm}$ in a spectrophotometer (UV-1800, Mapada, China). The sucrose concentration was analyzed using HPLC methods (U5000, Dionex, USA) with Cosmosil packed column sugar-D $(250 \times 4.6 \mathrm{~mm}$, Phenomenex, USA) using a refractive index detector. The mobile phase was acetonitrile and water in the ratio of 75:25 (\%) at a flow rate of 1 $\mathrm{ml} / \mathrm{min}$ at $30{ }^{\circ} \mathrm{C}$. The $\mathrm{pH}$ level was measured using fermenter inductors. The EPS concentration was determined as follows: the viscous culture broth $(50 \mathrm{ml})$ was diluted with four volumes of distilled water and centrifuged at $8000 \mathrm{rpm}$ for $30 \mathrm{~min}$ at $4{ }^{\circ} \mathrm{C}$ to separate the cells from the polysaccharide. The supernatant was precipitated using $10 \mathrm{ml}$ of isopropanol and the precipitate was dissolved in $0.8-0.9 \% \mathrm{NaCl}$ solution, reprecipitated in isopropanol and dried 
Table 1: Factors and their levels for P-B experimental design and the statistical analysis of factors

\begin{tabular}{lcccccc}
\hline Factor & Symbol & Low value (g/l) & High value (g/l) & Coefficient & $\begin{array}{c}\text { Standard } \\
\text { error }\end{array}$ & $P$-value \\
\hline Sucrose & $\mathrm{X}_{1}$ & 30 & 60 & 2.03 & 0.41 & $0.0026^{\mathrm{a}}$ \\
$\mathrm{Urea}$ & $\mathrm{X}_{2}$ & 0.1 & 0.5 & 0.42 & 0.41 & 0.2590 \\
$\mathrm{CaCO}_{3}$ & $\mathrm{X}_{3}$ & 1 & 5 & 2.68 & 0.41 & $0.0006^{\mathrm{a}}$ \\
$\mathrm{MgSO}_{4}$ & $\mathrm{X}_{4}$ & 0.2 & 0.6 & 0.46 & 0.41 & 0.2501 \\
$\mathrm{NaCl}$ & $\mathrm{X}_{5}$ & 0.2 & 0.6 & -0.97 & 0.41 & 0.0560 \\
$\mathrm{~K}_{2} \mathrm{HPO}_{4}$ & $\mathrm{X}_{6}$ & 0.2 & 0.6 & -1.72 & 0.41 & $0.0058^{\mathrm{a}}$ \\
Dummy1-5 & $\mathrm{X}_{7}-\mathrm{X}_{11}$ & - & - & - & - & - \\
\hline$R^{2}=0.9431 ;{ }^{2}$ statistically significant at 95\% confidence level. & & &
\end{tabular}

to a constant weight at $60{ }^{\circ} \mathrm{C}$ under partial vacuum.

\section{P-B design}

In order to determine which nutrients had a significant effect on EPS production, P-B design was used. Based on the P-B design, each factor was examined at two levels: -1 for a low level and +1 for a high level. Table 1 shows the factors under investigation as well as levels of each factor used in the experimental design. Five dummy factors (Dummy 1-5) were used to estimate the experimental error and check the adequacy of the first-order model. The mean of the EPS concentration obtained was taken as the response. Factors with $\mathrm{p}<0.05$ were considered to influence EPS production significantly.

\section{Path of steepest ascent method}

The path of steepest ascent is a procedure for moving sequentially along the path of steepest ascent to the region of the optimum for the direction of the maximum increase in the response [20]. Based on the results of the $P-B$ experimental design, the optimal level scope of each selected factor was examined by means of path of steepest ascent method. This point could be used as center point for optimization.

\section{Central composite design and response surface methodology}

Central composite design and response surface methodology was employed to optimize the three most significant factors (sucrose, $\mathrm{CaCO}_{3}$ and $\mathrm{K}_{2} \mathrm{HPO}_{4}$ ) for increasing EPS production, screened by $\mathrm{P}-\mathrm{B}$ design. These three independent factors were studied at five different levels $(-1.68,-1,0,+1$ and +1.68$)$ selected on the basis of our preliminary experimental work that indicated an optimum could be reached within these ranges. The variables were coded according to the regression equation Eq 1.
$x_{i}=\frac{X_{i}-X_{0}}{\Delta X_{i}} \quad i=1,2, \ldots, k$

In $\mathrm{Eq} 1$, $\mathrm{xi}$ is the coded independent factor, $\mathrm{Xi}$ is the real independent factor, $X 0$ is the value of $X i$ at the center point and $\Delta X i$ is the step change value.

Sixteen experiments were carried out with each at five levels (Table 2) in flasks. Experimental data were fitted to a second-order polynomial model and regression coefficients were obtained. The model equation for the analysis is given by:

$Y=\beta_{0}+\sum \beta_{i} x_{i}+\sum \beta_{i i} x_{i}^{2}+\sum \beta_{i j} x_{i} x_{j}$ $i=1,2, \ldots ., k \quad$ (2)

where $Y$ is the response variable, $\beta_{0}$ is the constant, $\beta_{i}$ is the coefficient for the linear effect, $\beta_{i i}$ is the coefficient for the quadratic effect, $\beta_{i j}$ is the coefficient for the interaction effect, and $x_{i}$ and $x_{j}$ are the coded independent factors. The quadratic equation ( $\mathrm{Eq} 2$ ) was used to plot surfaces for the variables.

\section{Data analysis}

Design Expert software package (version 8.05b) and Statistic (version 8.0, STATEASE Inc., Minneapolis, USA) were used for the experimental designs and regression analysis of the experimental data. The statistical analysis of the model was performed by analysis of variance (ANOVA). The significance of the regression coefficients and the associated probabilities $P(t)$ were determined by Student's ttest; The variance explained by the model is given by the multiple determination coefficient, $R^{2}$.

\section{Batch fermentation in 5-I fermenter}

To confirm the above predictions, further experiments were performed comparing the optimized medium in this work and an original medium used for the production of EPS by $B$. mucilaginosus CGMCC5766. 5-I fermenter was 
Table 2: Experimental design and results of the central composite design

\begin{tabular}{|c|c|c|c|c|c|}
\hline \multirow[b]{2}{*}{ Run } & \multirow{2}{*}{$\frac{\text { Sucrose }(g / l)}{X_{1}}$} & \multirow{2}{*}{$\frac{\mathrm{CaCO}_{3}(\mathrm{~g} / \mathrm{l})}{\mathrm{X}_{3}}$} & \multirow{2}{*}{$\frac{\mathrm{K}_{2} \mathrm{HPO}_{4}(\mathrm{~g} / \mathrm{l})}{\mathrm{X}_{6}}$} & \multicolumn{2}{|c|}{ EPS (g/l) } \\
\hline & & & & Observed & Predicted \\
\hline 1 & 55.0 & 4.50 & 0.10 & $18.34 \pm 0.45$ & 18.32 \\
\hline 2 & 55.0 & 4.50 & 0.30 & $15.14 \pm 0.40$ & 15.69 \\
\hline 3 & 55.0 & 5.50 & 0.10 & $19.26 \pm 0.50$ & 19.58 \\
\hline 4 & 55.0 & 5.50 & 0.30 & $16.05 \pm 0.30$ & 16.58 \\
\hline 5 & 65.0 & 4.50 & 0.10 & $19.10 \pm 0.40$ & 19.34 \\
\hline 6 & 65.0 & 4.50 & 0.30 & $18.83 \pm 0.50$ & 19.29 \\
\hline 7 & 65.0 & 5.50 & 0.10 & $19.33 \pm 0.54$ & 19.56 \\
\hline 8 & 65.0 & 5.50 & 0.30 & $18.35 \pm 0.42$ & 19.15 \\
\hline 9 & 51.6 & 5.00 & 0.20 & $17.04 \pm 0.45$ & 16.59 \\
\hline 10 & 68.4 & 5.00 & 0.20 & $20.27 \pm 0.55$ & 19.61 \\
\hline 11 & 60.0 & 4.16 & 0.20 & $19.00 \pm 0.65$ & 18.64 \\
\hline 12 & 60.0 & 5.84 & 0.20 & $20.33 \pm 0.52$ & 19.58 \\
\hline 13 & 60.0 & 5.00 & 0.03 & $20.05 \pm 0.48$ & 19.96 \\
\hline 14 & 60.0 & 5.00 & 0.37 & $18.42 \pm 0.53$ & 17.40 \\
\hline 15 & 60.0 & 5.00 & 0.20 & $21.56 \pm 0.45$ & 21.81 \\
\hline 16 & 60.0 & 5.00 & 0.20 & $21.87 \pm 0.47$ & 21.81 \\
\hline
\end{tabular}

Table 3: Experimental design and corresponding production response of EPS

\begin{tabular}{cccccccccccccc}
\hline Run & $\mathbf{X}_{\mathbf{1}}$ & $\mathbf{X}_{\mathbf{2}}$ & $\mathbf{X}_{\mathbf{3}}$ & $\mathbf{X}_{\mathbf{4}}$ & $\mathbf{X}_{\mathbf{5}}$ & $\mathbf{X}_{\mathbf{6}}$ & $\mathbf{X}_{\mathbf{7}}$ & $\mathbf{X}_{\mathbf{8}}$ & $\mathbf{X}_{\mathbf{9}}$ & $\mathbf{X}_{\mathbf{1 0}}$ & $\mathbf{X}_{\mathbf{1 1}}$ & \multicolumn{2}{c}{ EPS (g/l) } \\
\hline 1 & 1 & 1 & -1 & 1 & 1 & 1 & -1 & -1 & -1 & 1 & -1 & $10.56 \pm 0.23$ & 9.65 \\
2 & -1 & 1 & 1 & -1 & 1 & 1 & 1 & -1 & -1 & -1 & 1 & $9.87 \pm 0.20$ & 10.96 \\
3 & 1 & -1 & 1 & 1 & -1 & 1 & 1 & 1 & -1 & -1 & -1 & $12.95 \pm 0.15$ & 14.42 \\
4 & -1 & 1 & -1 & 1 & 1 & -1 & 1 & 1 & 1 & -1 & -1 & $6.87 \pm 0.10$ & 6.51 \\
5 & -1 & -1 & 1 & -1 & 1 & 1 & -1 & 1 & 1 & 1 & -1 & $8.59 \pm 0.18$ & 8.43 \\
6 & -1 & -1 & -1 & 1 & -1 & 1 & 1 & -1 & 1 & 1 & 1 & $8.51 \pm 0.15$ & 7.54 \\
7 & 1 & -1 & -1 & -1 & 1 & -1 & 1 & 1 & -1 & 1 & 1 & $9.61 \pm 0.14$ & 10.56 \\
8 & 1 & 1 & -1 & -1 & -1 & 1 & -1 & 1 & 1 & -1 & 1 & $9.56 \pm 0.16$ & 9.06 \\
9 & 1 & 1 & 1 & -1 & -1 & -1 & 1 & -1 & 1 & 1 & -1 & $20.80 \pm 0.52$ & 20.39 \\
10 & -1 & 1 & 1 & 1 & -1 & -1 & -1 & 1 & -1 & 1 & 1 & $15.20 \pm 0.22$ & 13.81 \\
11 & 1 & -1 & 1 & 1 & 1 & -1 & -1 & -1 & 1 & -1 & 1 & $19.04 \pm 0.45$ & 18.45 \\
12 & -1 & -1 & -1 & -1 & -1 & -1 & -1 & -1 & -1 & -1 & -1 & $9.17 \pm 0.15$ & 10.98 \\
\hline
\end{tabular}

filled with $3 \mathrm{I}$ of production medium and sterilized at $121{ }^{\circ} \mathrm{C}$ for $15 \mathrm{~min}$. It was inoculated with $5 \%$ $(\mathrm{V} / \mathrm{V})$ of 16-h-old culture. The fermenter was operated at $30{ }^{\circ} \mathrm{C}$ and agitation was shifted from 200 to $600 \mathrm{rpm}$ for a constant aeration of 1.0 volume of air per volume of liquid per minute (vvm).

\section{RESULTS}

\section{P-B experimental design}

To optimize the culture medium in the fermentation of EPS by $B$. mucilaginosus CGMCC5766, the components of the medium were examined. Previous studies indicated that the factors such as $\mathrm{Na}^{+}, \mathrm{Mg}^{2+}$ and phosphate might have important effects on the production of EPS during the fermentation of $B$. mucilaginosus $[9,14]$. In addition to these factors, others including urea and $\mathrm{Ca}^{2+}$ were also investigated in our experiment. The most important nutrient factors were screened by applying the P-B design as described in Table 3. Each independent factor was tested at two levels, a high (+1) and a low (-1) level and twelve trials were carried out. Based on the analysis by design expert, a first-order model could be obtained from the regression results of $\mathrm{P}-\mathrm{B}$ experiment:

$Y=11.73+2.03 X_{1}+0.42 X_{2}+2.68 X_{3}+0.46 X_{4}-0.97 X_{5}-$ $1.72 X_{6}$

(3)

The regression coefficients and determination coefficient $\left(R^{2}\right)$ for the linear regression model of EPS production are presented in Table 1 . The $R^{2}$-value was 0.9431 which indicated that the model was reasonable for the P-B design. Statistical analysis of the data showed that only sucrose, $\mathrm{CaCO}_{3}$ and $\mathrm{K}_{2} \mathrm{HPO}_{4}$ had confidence levels above $95 \%(\mathrm{P}<0.05)$ and were considered to influence EPS production 
significantly (Table 1). The other components in the media showed no significant influence EPS production for confidence levels below 95\%. Therefore, the three nutrient components of sucrose, $\mathrm{CaCO}_{3}$ and $\mathrm{K}_{2} \mathrm{HPO}_{4}$ were selected for further optimization with RSM.

\section{The path of steepest ascent}

Based on the first-order model equation obtained and regression results, we know that sucrose $\left(\mathrm{X}_{1}\right), \mathrm{CaCO}_{3}\left(\mathrm{X}_{3}\right)$ and $\mathrm{K}_{2} \mathrm{HPO}_{4} \quad\left(\mathrm{X}_{6}\right)$ were significant factors. Furthermore, the equation (3) shows that the coefficients of $X_{1}$ and $X_{3}$ are positive $(+2.03$ and +2.68 , respectively) while the coefficient of $X_{6}$ was negative $(-1.72)$, which suggests that the increase in concentrations of sucrose and $\mathrm{CaCO}_{3}$ and the decrease in concentration of $\mathrm{K}_{2} \mathrm{HPO}_{4}$ could have positive effect on the production of EPS. To search the proper direction to alter the levels of these three factors with the other factors fixed at zero level, the path of the steepest ascent was employed (data not shown). The results indicated that the concentration of EPS was highest when the concentrations of sucrose, $\mathrm{CaCO}_{3}$ and $\mathrm{K}_{2} \mathrm{HPO}_{4}$ were selected at $60 \mathrm{~g} / \mathrm{l}, 5.0 \mathrm{~g} / \mathrm{l}$ and $0.2 \mathrm{~g} / \mathrm{l}$, respectively. This shows that this level for each of the three factors was near the region of maximum EPS production response.

\section{Optimization of EPS production with RSM}

Based on the results of $\mathrm{P}-\mathrm{B}$ design, response surface methodology using central composite design (CCD) was employed to determine the optimal levels of the three selected factors (Sucrose, $\mathrm{CaCO}_{3}$ and $\mathrm{K}_{2} \mathrm{HPO}_{4}$ ), and a 3-factor-5level CCD with sixteen experiments was carried out (Table 2). A second-order polynomial function was fitted to the experimental EPS yield, resulting in the following regression equation:
$Y=21.810+0.897 X_{1}+0.279 X_{3}-0.762 X_{6}-1.311 X_{1}^{2}-$ $0.953 X_{3}^{2}-1.105 X_{6}^{2}-0.260 X_{1} X_{3}+0.645 X_{1} X_{3}-0.09 X_{3} X_{6}$ (4)

where $\mathrm{Y}$ is the predicted EPS production, and $\mathrm{X}_{1}$, $\mathrm{X}_{3}$ and $\mathrm{X}_{6}$ are coded values of sucrose, $\mathrm{CaCO}_{3}$ and $\mathrm{K}_{2} \mathrm{HPO}_{4}$ concentrations, respectively.

The statistical significance of equation (4) was checked by F-test and the ANOVA for the second-order polynomial is summarized in Table 4. If the F-test for the model is significant at $p<$ 0.05 , the model fits and can adequately account for the variation observed. The smaller $p$-value suggests that the corresponding variable was more significant. As shown in Table 5, the Pvalues for $X_{1}$ and $X_{6}$ were much less than 0.05 , which indicated that sucrose and $\mathrm{K}_{2} \mathrm{HPO}_{4}$ are more significant for the EPS production. Moreover, the $\mathrm{P}$-value of $\mathrm{X}_{1} \mathrm{X}_{6}(0.0761)$ was near 0.05 , which indicates that the interaction of sucrose and $\mathrm{K}_{2} \mathrm{HPO}_{4}$ is significant, namely, they are synergistic in influencing the EPS production. Furthermore, the goodness of the model could be checked by the determination coefficient $R^{2}$, which was calculated to be 0.9150 , indicating that 91.50 of the variability in the response could be explained by the model [21]. The p-value for lack of fit (0.1831) implied the lack of fit was not significant relative to the pure error.

Figs 1a-c illustrate the 3D response surface curves of EPS production for each pair of parameters by keeping the third factor constant at its zero level. These 3D plots and their respective contour plots provide a visual interpretation of the interaction between two factors and facilitated the identification of the optimum experimental conditions [22]. Based on the response surface analysis, the predicted maximum concentration of EPS was $22.04 \mathrm{~g} / \mathrm{l}$ at the optimal concentrations of sucrose, $\mathrm{CaCO}_{3}$ and $\mathrm{K}_{2} \mathrm{HPO}_{4}$ were $61.31 \mathrm{~g} / \mathrm{l}, 5.06 \mathrm{~g} / \mathrm{l}$ and $0.17 \mathrm{~g} / \mathrm{l}$,

Table 4: ANOVA for the second-order polynomial model

\begin{tabular}{llllll}
\hline Source & SS & DF & MS & $F$ & $P$ \\
\hline $\mathrm{X}_{1}$ & 10.992 & 1 & 10.99 & 228.76 & 0.0420 \\
$\mathrm{X}_{3}$ & 1.07 & 1 & 1.07 & 22.20 & 0.1331 \\
$\mathrm{X}_{6}$ & 7.92 & 1 & 7.92 & 164.87 & 0.0495 \\
$\mathrm{X}_{1}{ }^{2}$ & 15.91 & 1 & 15.91 & 331.13 & 0.0350 \\
$\mathrm{X}_{3}{ }^{2}$ & 8.42 & 1 & 8.42 & 175.26 & 0.0480 \\
$\mathrm{X}_{6}{ }^{2}$ & 11.32 & 1 & 11.32 & 235.61 & 0.0414 \\
$\mathrm{X}_{1} \mathrm{X}_{3}$ & 0.54 & 1 & 0.54 & 11.25 & 0.1844 \\
$\mathrm{X}_{1} \mathrm{X}_{6}$ & 3.33 & 1 & 3.33 & 69.27 & 0.0761 \\
$\mathrm{X}_{3} \mathrm{X}_{6}$ & 0.06 & 1 & 0.06 & 1.35 & 0.4526 \\
Residual error & 4.08 & 6 & 0.68 & & \\
Lack of fit & 4.04 & 5 & 0.81 & 16.80 & 0.1831 \\
Pure error & 0.0481 & 1 & 0.0481 & & \\
Total SS & 48.06 & 15 & & & \\
\hline$R^{2}=0.9150 ;$ & SS $=$ sum of squares; $D F=$ degrees of freedom' and $M S=$ mean square.
\end{tabular}




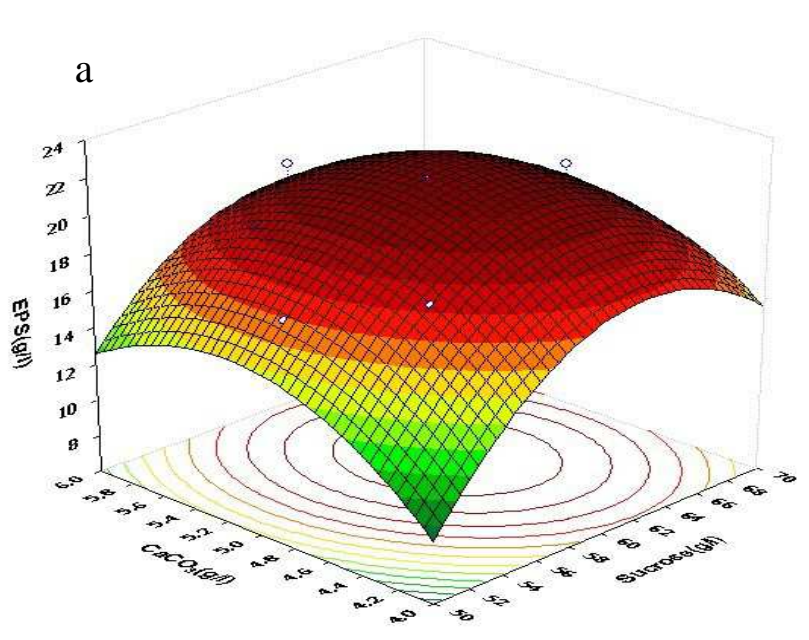

$\mathrm{b}$
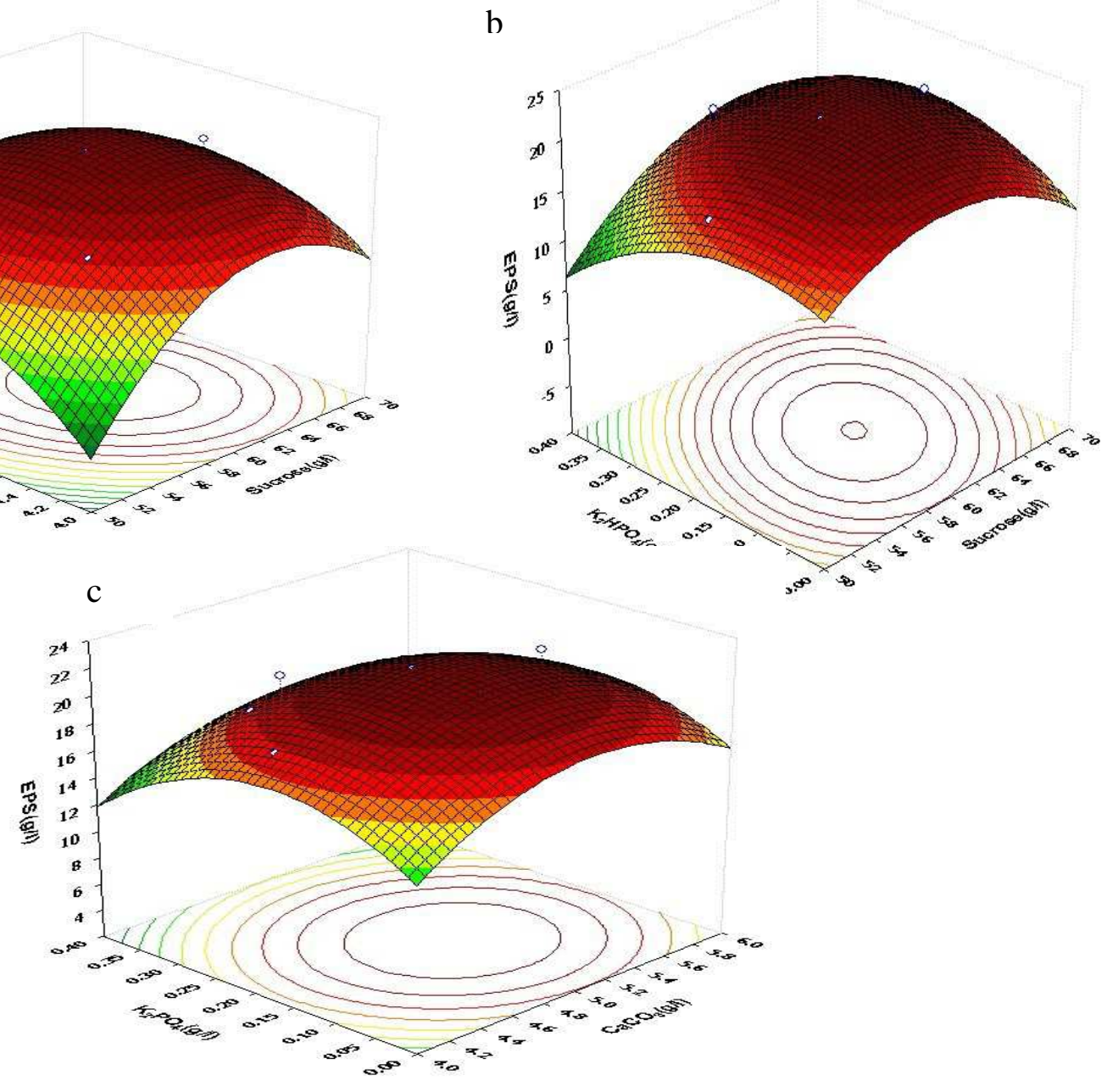

Fig 1: Response surface curve for EPS production by B. mucilaginosus CGMCC5766 showing the interaction between (a) Sucrose and $\mathrm{CaCO}_{3}$, (b) Sucrose and $\mathrm{K}_{2} \mathrm{HPO}_{4}$ and (c) $\mathrm{CaCO}_{3}$ and $\mathrm{K}_{2} \mathrm{HPO}_{4}$.

respectively, which was about 1.6-fold increase compared with that using the original medium $(14.05 \pm 0.25 \mathrm{~g} / \mathrm{l})$. In order to verify the predicted results, an experiment was performed with the optimized medium in flasks. As a result, $22.35 \pm 0.42 \mathrm{~g} / \mathrm{l}$ EPS was obtained which suggested that experimental values of EPS production were in close agreement with the model prediction.

\section{Time course of EPS production in 5-I fermenter}

Fermentation was scaled up from flasks to 5-I fermenter. Under the optimum conditions, the concentration of EPS was achieved $23.46 \pm 0.76$ $\mathrm{g} / \mathrm{l}$, which was higher than the original medium $(16.50 \pm 0.52 \mathrm{~g} / \mathrm{l})$ in $5-\mathrm{I}$ fermenter. And an increase of approximately $42.2 \%$ of EPS production was reached, which further proved the usefulness of the P-B design and RSM as optimization techniques to improve the production of EPS.

\section{DISCUSSION}

To optimize the culture medium in the fermentation of EPS by $B$. mucilaginosus CGMCC5766, the components of the medium were examined. $\mathrm{P}-\mathrm{B}$ experimental design shows that sucrose, $\mathrm{CaCO}_{3}$ and $\mathrm{K}_{2} \mathrm{HPO}_{4}$ are the main influencing factors for EPS production. It should be mentioned that the concentration of $\mathrm{CaCO}_{3}$ in the medium was higher than the nitrogen source. In our preliminary step, the biomass and EPS production of $B$. mucilaginosus CGMCC5766 were tested in the medium without $\mathrm{CaCO}_{3}$. It was found that without $\mathrm{CaCO}_{3}$, the biomass was very low and the secretion of EPS was limited, i.e., $0.46 \mathrm{~g} / \mathrm{l}$. However, when $\mathrm{CaCO}_{3}$ was added, the biomass and EPS production were notably increased. Similar results were found in xanthan fermentation [23]. It is noted that $\mathrm{CaCO}_{3}$ might play different roles in cell growth and polysaccharide biosynthesis. Calcium is essential for many microbial species, for maintaining cell wall rigidity, stabilizing protein conformations and facilitating signal communication [24] as well as 
balancing the $\mathrm{pH}$ of the culture medium [25]. Thus, increasing $\mathrm{CaCO}_{3}$ concentration in a suitable range will be helpful for cell growth, resulting in increased biomass and polysaccharide production.

\section{CONCLUSION}

RSM was successfully employed to optimize the medium components for EPS production from $B$. mucilaginosus CGMCC5766. The statistical methodology, combination of $\mathrm{P}-\mathrm{B}$ design with CCD was a reliable tool to optimize EPS production. Compared with the original culture medium, EPS concentration was increased from $14.05 \pm 0.25 \mathrm{~g} / \mathrm{l}$ to $22.35 \pm 0.42 \mathrm{~g} / \mathrm{l}$ after optimizing medium components. The fermentation under optimized condition was also investigated in 5-I fermenter, resulting in a further enhancement of the EPS concentration to $23.46 \pm 0.76 \mathrm{~g} / \mathrm{l}$. The optimization medium is considered fundamental and useful for the development of $B$. mucilaginosus CGMCC5766 cultivation process for efficient production of EPS on a large scale.

\section{ACKNOWLEDGEMENT}

This work was financially supported by the National High-Tech R\&D Program (No. 2011AA02A211), the National Natural Science Foundation of China (no. 31300026), the Nature Science Foundation of Jiangsu Province (No. BK2012117) and "Twelfth Five-Year" National Science and Technology Support Program (No. 2012BAD33B06). Hui Li and Jie Li contributed equally to this work.

\section{REFERENCES}

1. Kumar AS, Mody $K$, Jha B. Bacterial exopolysaccharides-a perception. J Basic Microbiol 2007; 47:103-117.

2. Becker A, Katzen F, Puhler A, lelpi L. Xanthan gum biosynthesis and application: a biochemical/genetic perspective. Appl Microbiol Biotechnol 1998; 50:145-152

3. Bayer AS, Eftekhar F, Tu J, Nast CC, Speert DP. Oxygen-dependent up-regulation of mucoid exopolysaccharide (alginate) production in Pseudomonas aeruginosa. Infect Immun 1990; 58:1344-1349.

4. Sa'-Correia I, Fialho AM, Videira $P$, Moreira $L M$, Marques AR, Albano $H$. Gellan gum biosynthesis in Sphingomonas paucimobilis ATCC 31461: genes, enzymes and exopolysaccharide production engineering. J Ind Microbiol Biotechnol 2002; 29. 170-176.

5. Duan XJ, Li Y, Xu Z, Tan WS. Effect of oxygen and shear stress on molecular weight of hyaluronic acid produced by Streptococcus zooepidemicus. J Microbiol Biotechnol 2008; 18: 718-724.

6. Parolis $H$, Parolis LA, Boán IF, Rodríguez-Valera $F$, Widmalm G, Manca MC, Jansson PE, Sutherland $I W$. The structure of the exopolysaccharide produced by the halophilic archaeon Haloferax mediterranei strain R4 (ATCC 33500). Carbohydr Res 1996; 295: 147-156.

7. Malinovskaya IM, Kosenko LV, Votselko SK, Podgorskii VS. Role of Bacillus mucilaginosus polysaccharide in degradation of silicate minerals. Microbiology 1990; 59: 49-55.

8. Chen $Y$, Lian B. Study on the flocculability of chromium ion by Bacillus mucilaginosus GY03 strain. Pedosphere 2005; 15: 225-231.

9. Deng SB, Bai RB, Hu XM, Luo Q. Characteristics of a bioflocculant produced by Bacillus mucilaginosus and its use in starch wastewater treatment. Appl Microbiol Biotechnol 2003; 60: 588-593.

10. Lian B, Chen Y, Zhao J, Teng HH, Zhu LJ, Yuan S. Microbial flocculation by Bacillus mucilaginosus: applications and mechanism. Bioresour Technol 2008; 99: 4825-4831.

11. Arockiasamy S, Banik RM. Optimization of gellan gum production by Sphingomonas Paucimobilis ATCC 31461 with nonionic surfactants using central composite design. J Biosci Bioeng 2008; 105: 204210.

12. Malinowska E, Krzyczkowski W, Lapienis G, Herold F. Improved simultaneous production of mycelial biomass and polysaccharides by submerged culture of Hericium erinaceum: optimization using a central composite rotatable design (CCRD). J Ind Microbiol Biotechnol 2009; 36: 1513-1527.

13. Wang YX, Lu ZX. Statistical optimization of media for extracellular polysaccharide by Pholiota squarrosa (Pers. ex Fr.) Quel. AS 5.245 under submerged cultivation. Biochem Eng J 2004; 20: 39-47.

14. He J, Zhen Q, Qiu N, Liu Z, Wang B, Shao Z, Yu Z. Medium optimization for the production of a novel bioflocculant from Halomonas sp. V3a' using response surface methodology. Bioresour Technol 2009; 100: 5922-5927.

15. Plackett RL, Burman JP. The design of optimum multifactorial experiments. Biometrika 1946; 33 : 305-325.

16. Tanyildizi SM, Ozer D, Elibol M. Optimization of aamylase production by Bacillus sp. using response surface methodology. Process Biochem 2005; 40: 2291-2296.

17. Gao J, Xu H, Li Q, Feng X, Li S. Optimization of medium for one-step fermentation of inulin extract from Jerusalem artichoke tubers using Paenibacillus polymyxa ZJ-9 to produce R,R-2,3-butanediol. Bioresour Technol 2010; 101: 7087-7093.

18. Chen XC, Ba, JX, Cao JM, Li ZJ, Xiong J, Zhang L, Hong $Y$, Ying HJ. Medium optimization for the production of cyclic adenosine 3,5'monophosphate by Microbacterium sp. no. 205 using response surface methodology. Bioresour Technol 2009; 100: 919-924.

19. Li J, Dou WF, Li Hui, Shi JS, Xu ZH, Li HZ. The preparation and rheological properties of the exopolysaccharides produced by Bacillus mucilaginous $S M-01$. Food and Fermentation Industries 2013; 39: 1-5.

20. Box GEP, Hunter JS, Hunter WG. Statistics for experimenters: design, innovation, and discovery. New York: John Wiley and Sons; 1978.

21. Li Y, Lu J, Gu G, Mao Z. Characterization of the enzymatic degradation of arabinoxylans in grist containing wheat malt using response surface methodology. J Am Soc Brew Chem 2005; 63: 171-176.

22. $\mathrm{Li} H, \mathrm{Xu} \mathrm{H}$, Li S, Feng XH, Ouyang PK. Optimization of exopolysaccharide welan gum production by Alcaligenes sp. CGMCC2428 with Tween-40 using response surface methodology. Carbohydr Polym 2012; 87: 1363-1368.

23. Umashankar $H$, Annadurai $G$, Chellapandian $M$, 
Krishnan MR. Influence of nutrients on cell growth and xanthan production by Xanthomonas campestris. Bioprocess Biosyst Eng 1996; 14: 307-309.

24. Maccio $D$, Fabra $A$, Castro $S$. Acidity and calcium interaction affect the growth of Bradyrhizobium $s p$. and attachment to peanut roots. Soil Biol Biochem 2002; 34: 201-208.

25. Hongo $M$, Nomura $Y$, Iwahara $M$. Novel method of lactic acid production by electrodialysis fermentation. Appl Environ Microbiol 1986; 52: 314-319. 